\title{
INVESTIGATION OF FRICTION HYSTERESIS USING A LABORATORY- SCALE TRIBOMETER
}

\author{
P. D. Neis ${ }^{1,2}$, P. De Baets ${ }^{2}$, Y. Perez Delgado ${ }^{2}$ and N. F. Ferreira ${ }^{1}$ \\ ${ }^{1}$ Federal University of Rio Grande do Sul, Brazil \\ ${ }^{2}$ Ghent University, Laboratory Soete, Belgium
}

\begin{abstract}
The current paper addresses the characterization of dynamic friction by using a laboratory-scale tribometer. A special post-processing script in MatLab has been developed in order to analyse the data from the experiments. A sine wave signal for the velocity is imposed, with three different frequencies and, consequently, acceleration and deceleration rates. A friction material from brakes, with nominal contact area of $254 \mathrm{~mm}^{2}$, was subjected to sliding against a commercially available brake disc (gray cast iron, diameter of $256 \mathrm{~mm}$ ). Some technical details and adjustments from the designed tribometer are showed and the results from the experiments are discussed. A friction hysteresis has been observed for all experimental curves, which exhibit loops in elliptical shape. A negative slope has been encountered for the curves when the imposed frequency is $1 \mathrm{~Hz}$ and $2 \mathrm{~Hz}$, while for the highest frequency $(4 \mathrm{~Hz})$ the slope is positive. The laboratory-scale tribometer, associated to the post-processing stage, is capable to successfully be used to characterize friction hysteresis effect.
\end{abstract}

Keywords friction, tribometer, hysteresis

\section{INTRODUCTION}

In the last decades, demand for high-accuracy positioning and tracking systems has been considerably increased in the machining and assembly industry. Not accurate information about the friction behavior can severely deteriorate control systems performance in the form of higher tracking errors, larger setting times, hunting and stick-slip phenomena [1]. Many parameters can influence the friction: material, surface roughness, apparent contact area, contact pressure, relative sliding velocity, ambient conditions, mechanical system parameters and the acceleration/deceleration rate [2].

The current paper addresses the influence of the last factor on the friction behavior of mating materials. A laboratory-scale tribometer has been modified in order to incorporate evaluations in different acceleration/deceleration rates of the slider against the disc. These modifications relate to changes in the control program of the machine (in Simulink) and the development of a post-processing script in MatLab for analysis of the results.

\section{DYNAMIC CHARACTERIZATION OF FRICTION}

For friction dynamic characterization, as during the changes in sliding velocity, a linear reciprocating tribometer is used. Typically, this equipment consists of a linear actuator (electrical or pneumatic), a displacement sensor, a load cell and a compartment where the friction elements are installed (Figure 1).

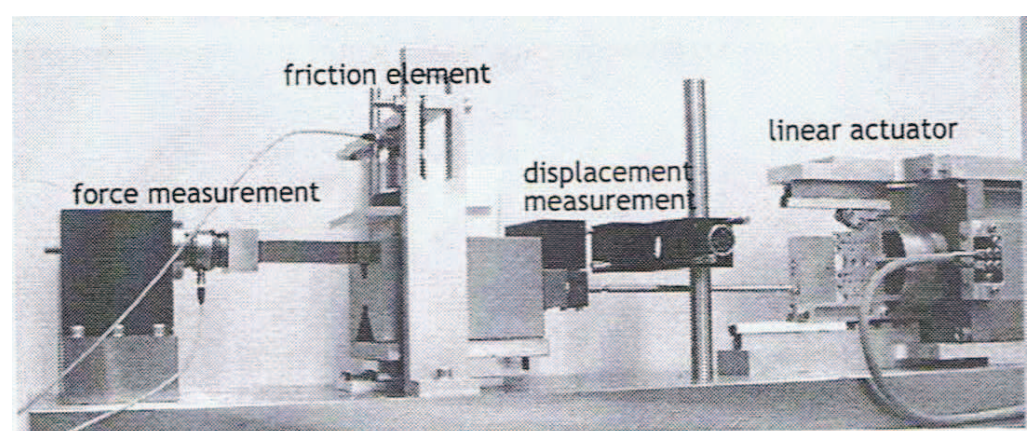

Figure 1. Linear Tribometer in Catholic University of Leuven [3] 
By means of a reciprocating tribometer is possible to simulate the geometry and motions experienced in many types of rubbing components whose normal operation results in periodic reversals in the direction of relative sliding. Friction coefficient is produced for forward and backward movements of the stroke. This equipment is very useful for studying static coefficient of friction, when the direction changes [4]. In this type of machine, the maximum frequency is inversely proportional to the set stroke. According to a manufacturer [5], their reciprocating tribometer achieves frequency of $2 \mathrm{~Hz}$ for a maximum stroke of $35 \mathrm{~mm}$. But for strokes lower than $2 \mathrm{~mm}$, frequencies up to $120 \mathrm{~Hz}$ can be achievable by using such equipment.

Figure 2 presents some typical results from linear reciprocating tribometer. In this graph, the large dots represent the steady-state friction-velocity curve and the friction hysteresis is shown by the loops a,b,c,d, and e, corresponding to the frequencies $0.1,0.25,0.5,1$ and 5 , respectively . Notice that in this graph the loops exhibit an elliptical shape for the friction hysteresis.

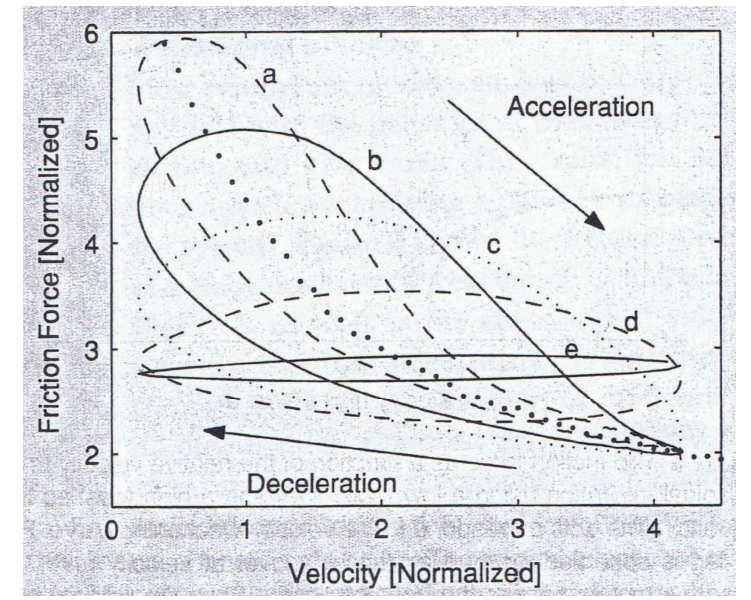

Figure 2. Dynamic characterization of friction force [1]

Other common shapes for the friction force vs. velocity curves (Figure 3) during friction hysteresis behaviour are known as loops clockwise and counter-clockwise loops [6].

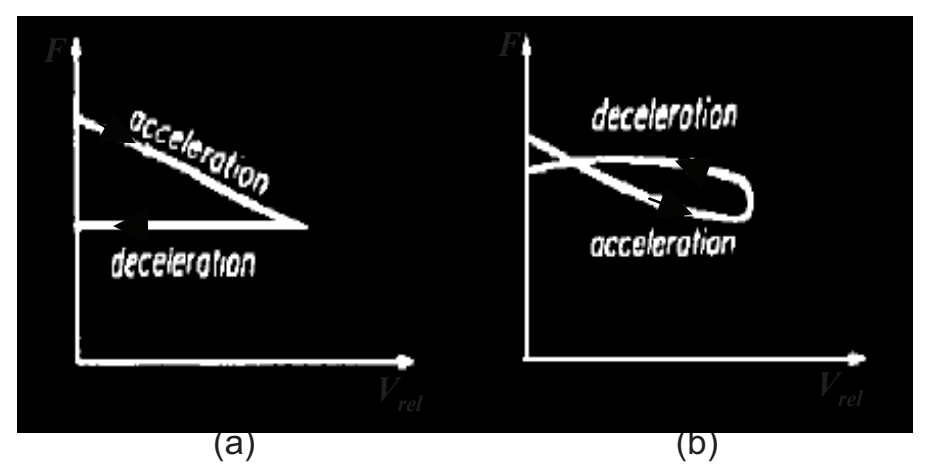

Fig. 3. Friction force-relative speed relations: (a) clockwise loops; (b) counter-clockwise loops (adapted from [6])

According to the literature [1,2], friction hysteresis effect is associated with the instantaneous real contact area, which is not only a function of the instantaneous relative sliding velocity, but also of the time available for the system to adapt to the situation corresponding to the actual sliding speed.

\section{EXPERIMENTAL APPARATUS}

Figure 4 shows the experimental apparatus used in the current research, where both the rotating and actuator systems of the tribometer are presented. 

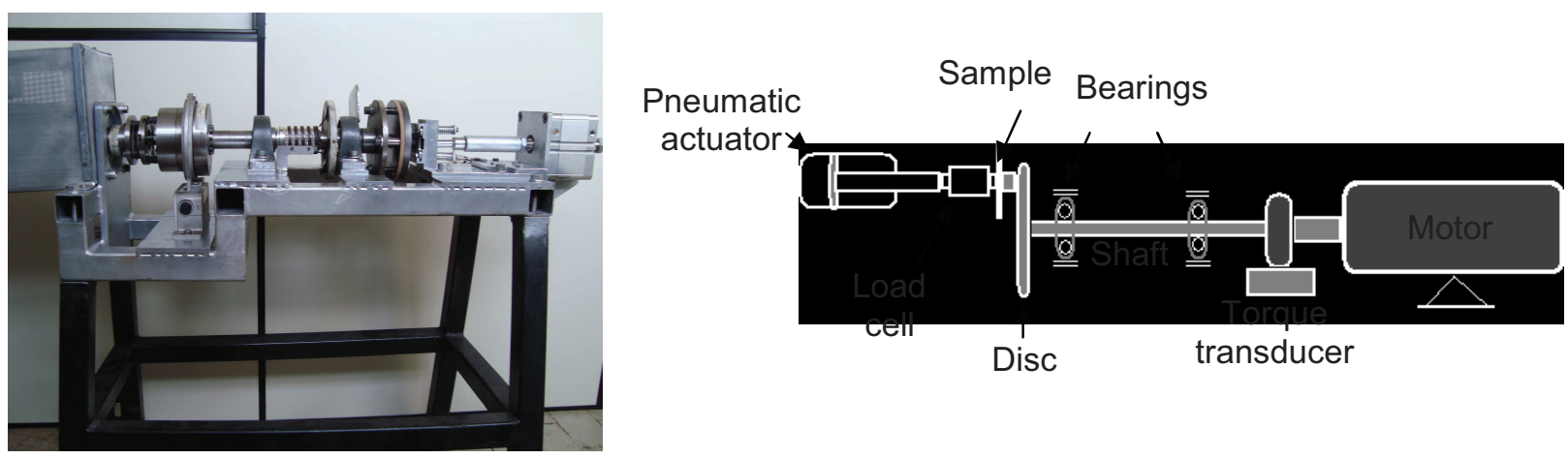

Figure 4. Experimental apparatus: (a) photograph and (b) scheme of the tribometer

The laboratory-scale tribometer (Fig. 4) has been designed to match the range of contact pressure and sliding speed as those in real car brakes, according to a previous study [7]. In this equipment, the sample has a small size in order to allow versatility during the tests and reduce the costs.

Regarding to the load/actuator system, the tribometer can operate in two different modes:

I) Constant force mode: the normal force on the disc, which is done by means a pneumatic actuator, is kept constant over time during the tests. At the same time, the braking torque remains free to vary according to the changes in the coefficient of friction.

II) Constant torque mode: the braking torque is kept constant over time during the tests. This is done by a closed loop process that controls the applied force at each fraction of a second. A feedback from the current torque is performed by means of a torque transducer installed on the tribometer shaft.

Regarding to the rotating system, the tribometer can operate in three modes:

I) Constant drag mode: rotation speed of the disc is kept constant over time during the tests.

II) Disc deceleration mode: the rotation speed of the disc decreases at a pre-set rate as the braking proceeds, similar to the braking process in cars and the tests performed on brake dynamometers.

III) Wave mode: this option allow us to characterize friction dynamics, such as friction hysteresis in velocity. For doing that, a sine or squared wave signal for the velocity is imposed by the servomotor of the tribometer (Figure 5). Different acceleration and deceleration rates can be tested by altering the frequency of the imposed velocity.

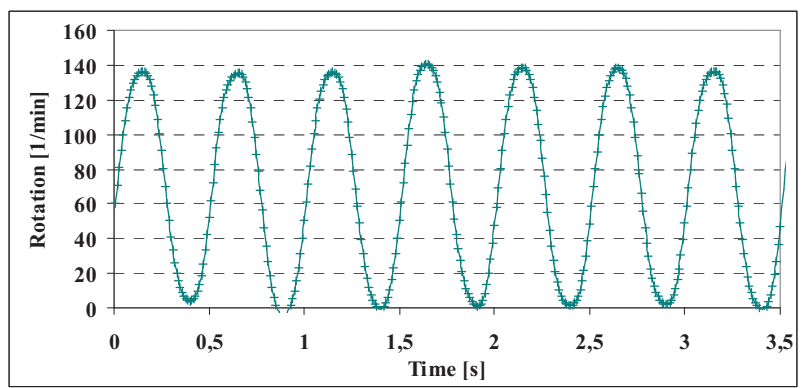

(a)

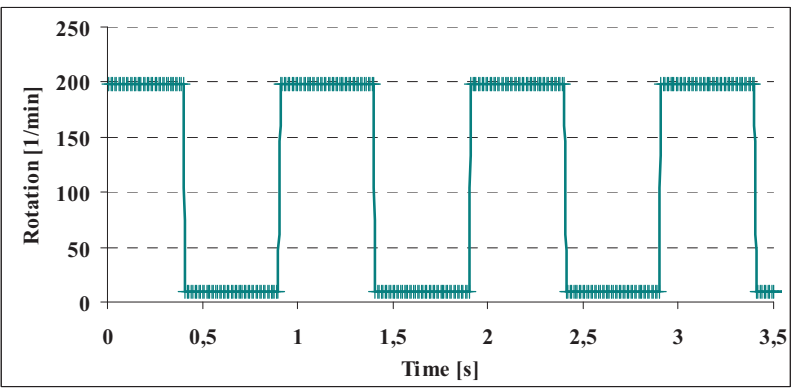

(b)

Figure 5 - Type of waves for the velocity in the wave mode: a) Sine wave; b) Squared wave.

Table 1 summarizes the general characteristics of the described machine, where the range of frequencies for the imposed velocity in the wave mode $(0$ to $4 \mathrm{~Hz})$ is showed. These frequencies are valid between 0.1 to $200 \mathrm{rpm}$ and for a maximum load of $400 \mathrm{~N}$. When using $4 \mathrm{~Hz}$, a rotation speed higher than $200 \mathrm{rpm}$ or a load higher than $400 \mathrm{~N}$ may put the motor inverter in "over-torque limit" due to the high starting torque required from the servomotor. 
Table 1. General characteristics of the tribometer

\begin{tabular}{|l|l|}
\hline Normal load & 0 to $4200 \mathrm{~N}$ \\
\hline Motor power & $11 \mathrm{~kW}$ \\
\hline Sliding radius & 27 to $54 \mathrm{~mm}$ \\
\hline Rotating disc speed & 0 to $4500 \mathrm{rpm}$ \\
\hline Disc diameter & $159 \mathrm{~mm}$ \\
\hline $\begin{array}{l}\text { Frequency for the imposed velocity in } \\
\text { the wave mode }\end{array}$ & 0 to $4 \mathrm{~Hz}$ \\
\hline
\end{tabular}

\section{SET UP OF THE TESTS}

\subsection{Matlab script for post-processing}

Due to the high dynamic involved in the current tests, performed with wave mode, both hardware and software filters (type "pass-band") have been removed. A calibration procedure has been previously done in order to determine the torque due to the inertia of the tribometer shaft during the accelerations and decelerations. These curves are used in a post-processing script, developed in MatLab. During postprocessing stage, the signal noises are filtered (Fig. 6-a) and the friction torque (net torque) is determined by subtracting the total torque, measured during the experiments, by the torque due to the inertia in the tribometer shaft (Fig. 6-b).

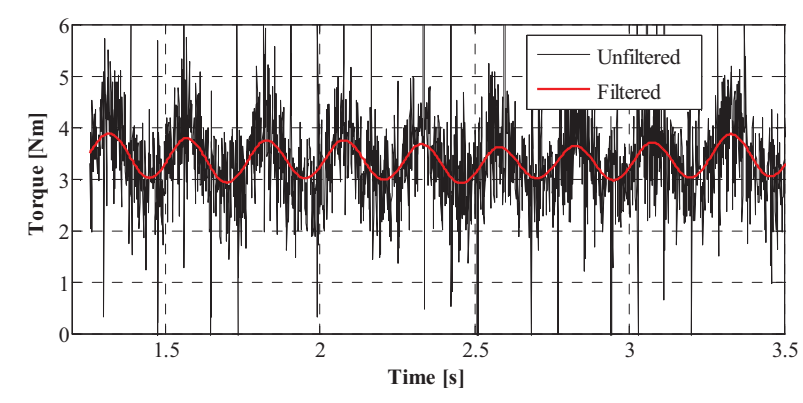

(a)

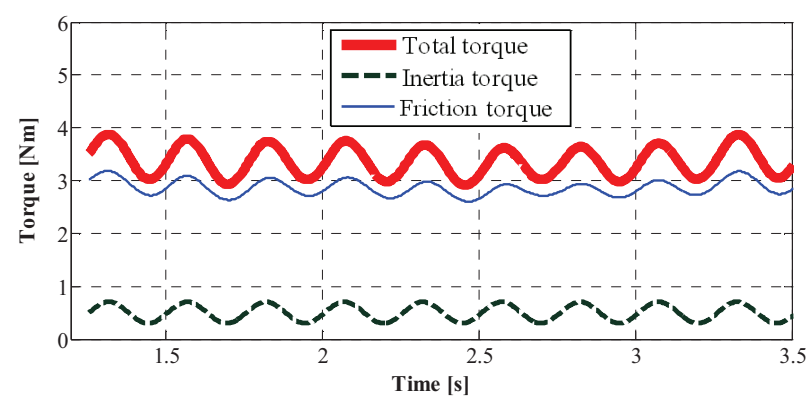

(b)

Figure 6. Post-processing the data: a) filtering the signal; b) determining the friction torque.

\subsection{Samples preparation}

Table 2 shows the formulation of the newly formulated sample used in this study. All the constituents were weighed using an analytical balance and mixed for 10 min by using a commercial blender.

Table 2. Formulation of the sample

\begin{tabular}{lc}
\hline Constituents & Content in wt $\%$ \\
\hline Binder & 43 \\
Metal & 0.6 \\
Friction Modifiers & 15 \\
Filler & 17 \\
Fibers & 20 \\
Others & 4.4 \\
\hline
\end{tabular}


The final mixture was loaded into a cylindrical mold. Post-curing was carried out at a constant temperature of $180^{\circ} \mathrm{C}$ by placing the samples in a preheated. This friction material is currently in development process to become a commercial brake pad for light vehicles by a manufacturer in Brazil.

Sample was machined in a circular shape with nominal contact area of $254 \mathrm{~mm}^{2}$ (Fig. 7). As counter surface, a commercially available brake disc (gray cast iron, diameter of $256 \mathrm{~mm}$, thickness of $6 \mathrm{~mm}$ ) has been used.

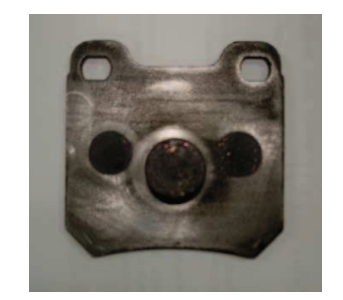

Figure 7 - Sample geometry.

\subsection{Operating Parameters}

In order to eliminate transient effects, such as running-in, a pre-run sliding of $1 \mathrm{~h}$ duration (constant load and speed of $150 \mathrm{~N}$ and $1.5 \mathrm{~m} / \mathrm{s}$, respectively) has been done prior the tests. Table 3 shows the operating conditions used in each experiment, where a sine wave signal has been set for the imposed speed.

Table 3. Operating parameters

\begin{tabular}{|c|c|c|c|c|}
\hline $\begin{array}{c}\text { Test } \\
\text { Number }\end{array}$ & $\begin{array}{c}\text { Frequency } \\
{[\mathbf{H z}]}\end{array}$ & $\begin{array}{c}\text { Acceleration/deceleration } \\
\text { rate }\left[\mathbf{m m} / \mathbf{s}^{2}\right]\end{array}$ & $\begin{array}{c}\text { Max speed } \\
{[\mathbf{m m} / \mathbf{s}]}\end{array}$ & $\begin{array}{c}\text { Min speed } \\
{[\mathbf{m m} / \mathbf{s}]}\end{array}$ \\
\hline 1 & 1 & 100 & $50.4(12 \mathrm{rpm})$ & $4.2(1 \mathrm{rpm})$ \\
\hline 2 & 2 & 200 & $50.4(12 \mathrm{rpm})$ & $4.2(1 \mathrm{rpm})$ \\
\hline 3 & 4 & 400 & $50.4(12 \mathrm{rpm})$ & $4.2(1 \mathrm{rpm})$ \\
\hline
\end{tabular}

A normal constant load of $400 \mathrm{~N}$ was adjusted during all tests, resulting in a nominal pressure of $1,57 \mathrm{MPa}$, whose value is equivalent to a typical braking condition that occur in light vehicles [7]. Data acquisition sampling rate was set in $1 \mathrm{kHz}$ and $10 \mathrm{~s}$ of duration for each test.

\section{EXPERIMENTAL RESULTS}

Figure 8 shows the friction hysteresis behaviour for the test number 1 , corresponding to the frequency $1 \mathrm{~Hz}$. A negative slope of -0.0012 has been encountered for this curve, where this parameter was determined by subtracting $\operatorname{cof}_{2}$ by $\operatorname{cof}_{1}$, divided by the difference between the maximum and minimum rotation (rpm).

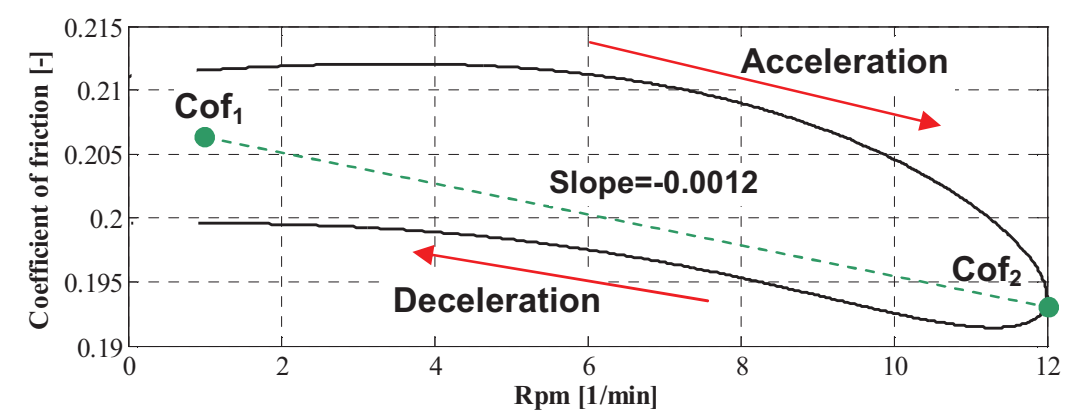

Figure 8. Friction hysteresis for the test 1 
Figure 9 shows the friction hysteresis curve for the test number 2, corresponding to the frequency $2 \mathrm{~Hz}$. Comparing the slope of this curve to those from the test 1 , not significant difference has been encountered.

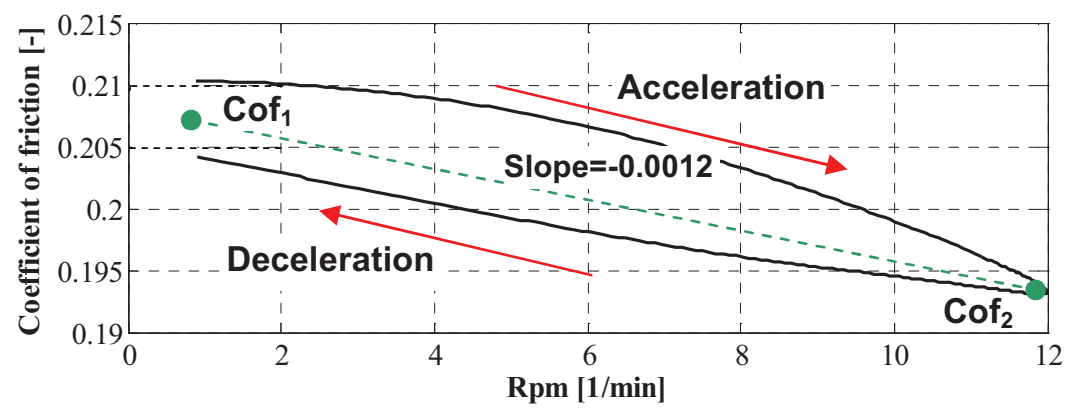

Figure 9. Friction hysteresis for the test 2

Figure 10 shows the friction hsyteresis curve for the test number 3 , corresponding to the frequency $4 \mathrm{~Hz}$. Unlike the previous results, a positive slope of +0.0011 has been encountered for this curve.

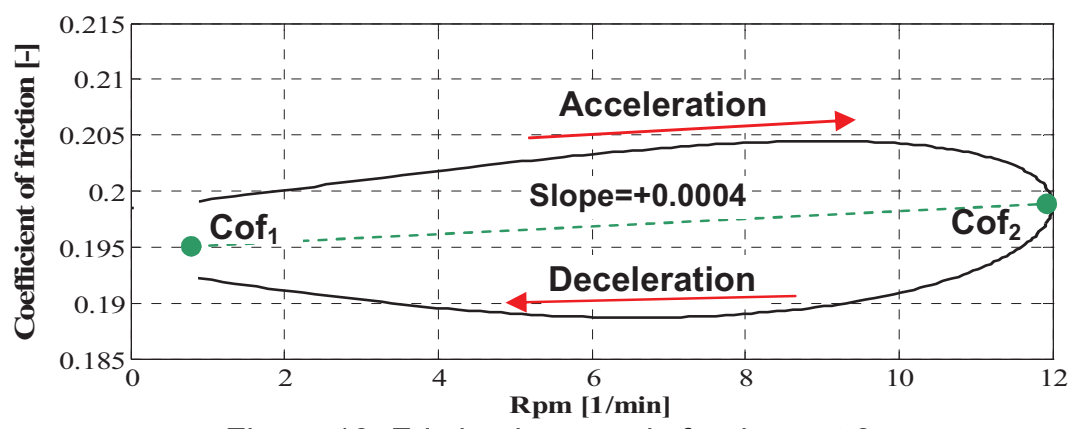

Figure 10. Friction hysteresis for the test 3

All experimentally obtained curves (Figs. 10, 11 and 12) reveal an eliptical shape for the friction hysteresis. This behavior is similar to those found by [1], which were previously shown in the Fig. 2.

Table 4 summarizes the experimental results for all tests. Notice that the curve slopes change the signal (negative to positive) only when the frequency is considerably increased, as in the test $3(4 \mathrm{~Hz})$. It seems that the influence of changes in acceleration/deceleration rates on the friction is strongly non-linear, since no significative differences in the curve slopes have been observed for the frequencies $1 \mathrm{~Hz}$ and $2 \mathrm{~Hz}$, as during the tests 1 and 2, respectively.

Table 4. Experimental results

\begin{tabular}{|c|c|c|c|}
\hline $\begin{array}{c}\text { Test } \\
\text { Number }\end{array}$ & Cof $_{\mathbf{1}}$ & Cof $_{\mathbf{2}}$ & Slope \\
\hline 1 & 0.206 & 0.193 & -0.0012 \\
\hline 2 & 0.207 & 0.194 & -0.0012 \\
\hline 3 & 0.195 & 0.199 & 0.0004 \\
\hline
\end{tabular}

A lower coefficient of friction has been encountered in the beginning of the sliding process (parameter Cof $_{1}$ ) for the test 3. A possible explanation for this phenomenon is found in the non-uniform surface conditions (mainly the surface roughness) of the cast iron disc and also variations in local chemical composition, causing the friction to change during disc rotation. In depth analysis of these effects will need further research effort that is beyond the scope of the present study.

\section{CONCLUSIONS}

A friction hysteresis has been observed for all experimental curves, which exhibit loops in elliptical shape. A negative slope has been encountered for the curves when the imposed frequency is $1 \mathrm{~Hz}$ and $2 \mathrm{~Hz}$. On the 
other hand, for the highest frequency $(4 \mathrm{~Hz})$ the slope is positive. This general behavior is similar to those published by [1].

The laboratory-scale tribometer allow us to test a wide range of acceleration and deceleration rates. For this reason, this equipment associated with the post-processing script currently developed, is capable to successfully be used to characterize friction hysteresis effect.

\section{NOMENCLATURE}

$\mathrm{Cof}_{1}$ average of coefficient of friction in the minimum rotation (1 rpm)

$\mathrm{Cof}_{2}$ average of coefficient of friction in the maximum rotation (12 rpm)

\section{ACKNOWLEDGEMENTS}

Authors are grateful to Financial support of FWO project G022506 and Erasmus exchange program - Euro Brazilian Windows II.

Special thanks also to Jonas Giacomeli by the technical support supplied.

\section{REFERENCES}

[1] F. Al Bender; J. Swevers, Characterization of Friction Force Dynamics, IEE Control Systems Magazine, 2008.

[2] F. Van de Velde, P. De Baets, Comparison of Two Stick-Slip Tester and Recommendations for Repeatable And Significant Stick-Slip Testing, Tribotest Journal 3-4, 1997.

[3] F. Al-Bender, H. Van Brussel, T. Janssens, K. De Moerlooze, Experimental Characterization of Friction, Brochure about the facilities in the Faculty of Engineering in Katholieke Univesiteit Leuven, Belgium.

[4] ASTM G133 - 05(2010), Standard Test Method for Linearly Reciprocating Ball-on-Flat Sliding Wear, 2010

[5] Nanovea tribometers, Company website. Available in: <http://www.nanovea.com/Tribometers.html>, Access at 15th of Dez 2010.

[6] B.N.J. Person, Sliding friction: physical principles and applications, Springer, Berlin. ISBN(1998) 3-54063296-4.

[7] M. B. Infantini, Variáveis de desempenho dos sistemas de freios. Master dissertation, 96 pages. Federal University of Rio Grande do Sul, Brazil, 2008. 